Applying an intervention framework to assess North Carolina's adolescent pregnancy prevention efforts

By: Christine D. Chambers and Alice Ma.

Chambers, Brittany D., Ma, Alice. (2016). Applying an intervention framework to assess North Carolina's adolescent pregnancy prevention efforts. Sexual \& Reproductive Healthcare, 8, June 2016, 102-104.

Made available courtesy of Elsevier: http://dx.doi.org/10.1016/j.srhc.2016.02.003

****() Elsevier. Reprinted with permission. No further reproduction is authorized without written permission from Elsevier. This version of the document is not the version of record. Figures and/or pictures may be missing from this format of the document. ***

\title{
(i) $\ominus$
}

EY NC ND This work is licensed under a Creative Commons AttributionNonCommercial-NoDerivatives 4.0 International License.

\section{Abstract:}

\section{Purpose}

We assessed the extent to which implementing adolescent pregnancy prevention programs in conjunction with three level implementation strategies reduces adolescent pregnancy rates at the county-level in North Carolina (NC).

\section{Methods}

Fixsen and colleagues' (2005) three levels of implementation were used to organize the prevention strategies: core (e.g., training, fidelity monitoring), organizational (e.g., administrative support), and external (e.g., community resources).

\section{Results}

Counties that had adolescent friendly clinic/services (external) were more likely to report lower adolescent pregnancy rates in comparison to counties that did not have access to such services.

\section{Conclusions}

Findings suggest external implementation strategies are key to reducing adolescent pregnancy rates.

Keywords: Adolescent pregnancy | Teen pregnancy prevention | Intervention frameworks

\section{Article:}




\section{Introduction}

There has been a substantial decline in adolescent pregnancy rates in the United States (US) over the past decade [1]. North Carolina (NC) is ranked 20th, out of 50 states [2]. Although the state's adolescent pregnancy rate has decreased by $11 \%$ between 2012 and 2013 alone, adolescent pregnancy rates among NC's 100 counties range from 9.6 to 77.6 , averaging 56.9 pregnancies per 1000 females aged 15-19 [2]. The average adolescent pregnancy rate for NC is nearly double that of the US rate of 26.5 [1]. Similar to the US, racial and economic disparities are seen among counties in $\mathrm{NC}$ with higher adolescent pregnancy rates compared to those with lower rates [1] and [2].

Evidence-based adolescent pregnancy prevention programs have rendered promising results in delaying sexual debut and decreasing adolescent pregnancy [3]. The purpose of this study was to assess the extent to which implementing adolescent pregnancy prevention programs in conjunction with core, organizational, and external implementation strategies reduces adolescent pregnancy rates at the county-level in NC.

\section{Methods}

Data were compiled from 20 stakeholders' (Partners for Adolescent Sexual Health (PASH) of NC) work and involvement with adolescent pregnancy prevention programs and services (e.g., HiTOPS, Inc. ${ }^{1}$ ) across the 100 counties of NC. PASH of NC met quarterly to review and update data over the course of one-year (i.e., September 2013-2014). Data consisted of adolescent pregnancy prevention strategies being implemented at the local level and each county's five-year adolescent pregnancy rate. This study was limited to 48 counties implementing evidence-based adolescent pregnancy programs. There were 15 adolescent pregnancy prevention programs implemented throughout NC during 2013-2014. ${ }^{2}$ All counties were receiving local, state, and/or federal funding for program implementation.

The researchers used Fixsen and colleagues' [4] three levels of implementation to organize the prevention strategies: (1) core implementation strategies include support programming for staff in obtaining high-fidelity behaviors (e.g., training, fidelity monitoring, coaching); (2) organizational implementation strategies provide the infrastructure, credibility, and support for core implementation strategies (e.g., administrative support, program evaluation); and (3) external implementation strategies refer to the context in which programs are implemented and includes economic (e.g., funding priorities), political (e.g., federal and state laws), and social (e.g., community resources) factors. Fixen and colleagues [4] posit that these three levels of implementation are interconnected where high-fidelity behaviors are achieved when there is a strong core with supportive organizational and external implementation strategies to provide multilevel approaches to address health issues.

\section{Measures}

Five-year adolescent pregnancy rate. The average adolescent pregnancy rate for years 20092013 for each county in NC. $\underline{3}$ These are the most current adolescent pregnancy rates publicly available and overlap with the time-frame of interventions. 
Adolescent pregnancy prevention programs. Counties implementing primary and/or secondary adolescent pregnancy prevention program(s).

Core implementation strategy. Educator(s) in the county who are trained to implement the evidence-based curriculum, Making Proud Choices (MPC), ${ }^{4}$ in addition to other adolescent pregnancy prevention programs.

Organizational implementation strategies. (1) Counties whose lesson plans for sexual and reproductive health meet NC's Healthy Youth Act (HYA) requirements and (2) counties that participate in the Working to Institutionalize Sex Education (WISE) project and/or support the Centers for Disease Control and Prevention's (CDC) Division of Adolescent and School Health (DASH) strategies to prevent sexual risk factors among adolescent youth. $\frac{5}{}$

External implementation strategies. Counties that have a local adolescent pregnancy prevention coalition and provide adolescent friendly clinics/services (community resources) in the area.

Three level implementation strategies. "All" were counties implementing at least one strategy from core, organizational and external implementation strategies. "Two" refers to counties that implemented at least one strategy from two of the three levels of implementation strategies. "One" included counties that implemented one strategy. "None" suggest counties were not implementing any strategies.

\section{Data analysis}

We calculated descriptive statistics to determine the percentage of counties in NC implementing core, organizational, and external level implementation strategies. Next, we conducted a linear multiple regression analysis to assess the extent to which implementing adolescent pregnancy prevention programs, in conjunction with core, organizational, and external implementation strategies, reduced adolescent pregnancy rates at the county-level. All analyses were performed using IBM SPSS Statistics 22 (Armonk, NY).

\section{Results}

All $(\mathrm{N}=48)$ counties were implementing evidence-based adolescent pregnancy prevention programs in NC (see Table 1). The average 5-year adolescent pregnancy rate was 56.9 per 1000 females aged 15-19 (see Table 1). Approximately $44 \%$ of the 48 counties trained health educators to implement MPC (core), 33\% participated and/or supported WISE or WISE + CDC's DASH (organizational), and 64\% of their lesson plans for sexual and reproductive health met HYA's requirements (organizational) (see Table 1). Relatively few counties had local adolescent pregnancy prevention coalitions (14.6\%) and adolescent friendly clinic/services (18.8\%) (external) (see Table 1). Additionally, only $18.8 \%$ of counties were concurrently implementing all three levels of implementation strategies (see Table 1). 


\begin{tabular}{|c|c|c|}
\hline & $\mathrm{n} /$ mean & Percent/SD \\
\hline 5-Year teen pregnancy rate & 56.9 & 16.9 \\
\hline \multicolumn{3}{|c|}{ Core implementation strategy } \\
\hline \multicolumn{3}{|c|}{ Educator(s) trained to implement MPC } \\
\hline No & 27 & $56.3 \%$ \\
\hline Yes & 21 & $43.8 \%$ \\
\hline \multicolumn{3}{|c|}{ Organizational implementation strategies } \\
\hline \multicolumn{3}{|c|}{$\begin{array}{l}\text { WISE or WISE + CDC Division of Adolescent } \\
\text { and Health }\end{array}$} \\
\hline No & 32 & $66.7 \%$ \\
\hline Yes & 16 & $33.3 \%$ \\
\hline \multicolumn{3}{|c|}{$\begin{array}{l}\text { Lesson plans that meet HYA requirements } \\
\text { provided to schools }\end{array}$} \\
\hline No & 17 & $35.4 \%$ \\
\hline Yes & 31 & $64.6 \%$ \\
\hline \multicolumn{3}{|c|}{ External implementation strategies } \\
\hline \multicolumn{3}{|c|}{ Local pregnancy prevention coalition } \\
\hline No & 41 & $85.4 \%$ \\
\hline Yes & 7 & $14.6 \%$ \\
\hline \multicolumn{3}{|c|}{ Teen friendly clinic and services } \\
\hline No & 39 & $81.3 \%$ \\
\hline Yes & 9 & $18.8 \%$ \\
\hline \multicolumn{3}{|l|}{ Funding } \\
\hline No & 0 & $0 \%$ \\
\hline Yes & 48 & $100 \%$ \\
\hline \multicolumn{3}{|c|}{ Three-level implementation strategies } \\
\hline All & 9 & $18.8 \%$ \\
\hline Two & 11 & $22.9 \%$ \\
\hline One & 21 & $43.8 \%$ \\
\hline None & 7 & $14.6 \%$ \\
\hline
\end{tabular}

A significant negative association was found between adolescent pregnancy rates and the availability of local adolescent friendly clinics/services (external) at the county-level $(\beta=-0.412, p=.003)$ (see Table 2). Additionally, a marginally significant positive relationship was found between counties implementing none compared to all three levels of implementation strategies, and adolescent pregnancy rates $(\beta=14.956, p=.086)$ (data not provided). 


\begin{tabular}{|c|c|c|}
\hline & $\beta(95 \% \mathrm{Cl})$ & SE \\
\hline \multicolumn{3}{|l|}{ Core implementation strategy } \\
\hline Educator(s) trained to implement MPC & $1.18(-1.19,11.08)$ & 5.311 \\
\hline \multicolumn{3}{|l|}{ Organizational implementation strategies } \\
\hline $\begin{array}{l}\text { WISE or WISE + CDC Division of } \\
\text { Adolescent and School Health }\end{array}$ & $3.348(-1.45,13.55)$ & 5.243 \\
\hline $\begin{array}{l}\text { Lesson plans that meet HYA } \\
\text { requirements provided to schools }\end{array}$ & $-1.88(-11.27,0.44)$ & 5.28 \\
\hline \multicolumn{3}{|l|}{ External implementation strategies } \\
\hline Local pregnancy prevention coalition & $3.997(-5.20,16.41)$ & 7,096 \\
\hline Adolescent friendly clinics/services* & $-17,607(-27,25,-5,54)$ & 6.771 \\
\hline Constant $* *$ & $59.215(50.96,60.62)$ & 4,386 \\
\hline \multicolumn{3}{|l|}{ Model staristics } \\
\hline$F$ & 1.464 & \\
\hline df & 5.42 & \\
\hline Adjusted $R^{2}$ & 0,085 & \\
\hline
\end{tabular}

\section{Discussion}

This study describes both barriers to implementing adolescent pregnancy prevention programs in $\mathrm{NC}$, as well as key factors associated with reducing adolescent pregnancy rates on the countylevel.

Only 48 out of 100 counties in NC implemented evidence-based adolescent pregnancy prevention programs. Among the 48 counties, all were receiving local, state, and/or federal funds to implement these programs. Only one external implementation strategy, access to adolescent friendly clinics/services, was associated with program implementation and reducing adolescent pregnancy rates. This indicates that external strategies (i.e., community resources) are important factors in reducing adolescent pregnancy rates. Furthermore, these results suggest there is not an interconnection between the three levels of implementation strategies.

The strengths of this study include the following: data were compiled by key stakeholders in pregnancy prevention, information on multilevel strategies was collected, and inferences were able to be made on the county-level. However, our findings should be evaluated in the geographically-specific context of NC.

Future research should explore whether locating adolescent friendly clinics or services in highrisk communities, or near institutions serving teens (e.g., high schools), impacts adolescent pregnancy rates [5]. Additionally, it would be useful to investigate what factors are associated with counties that implement adolescent pregnancy prevention programs.

\section{Implications and contributions}


Adolescent pregnancy rates are decreasing in the US, due in part to multiple implementation strategies. Findings suggest that external implementation strategies, in conjunction with adolescent pregnancy prevention programs, are key to reducing adolescent pregnancy rates. Funding mechanisms to support external implementation strategies are needed.

\section{Acknowledgements}

We would like to thank Rodney Crownover, MSW, and the Partners for Adolescent Sexual Health of North Carolina for providing us access to the data analyzed in this study.

\section{References}

[1] Centers for Disease Control and Prevention [CDC]. About teen pregnancy. http://www.cdc.gov/teenpregnancy/about/index.htm; 2015 [accessed 06.21.15].

[2] Sexual Health Initiatives for Teens [SHIFT]. 2013 Teen Pregnancies. http://www.shiftnc.org/data/map/northcarolina; 2014 [accessed 06.21.15].

[3] Kirby D. Abstinence, sex, and STD/HIV education programs for teens: their impact on sexual behavior, pregnancy, and sexually transmitted disease. Annu Rev Sex Res 2007;18(1):143-77.

[4] Fixsen DL, Naoom SF, Blase KA, Friedman RM, Wallace F. Implementation research: a synthesis of the literature. Tampa (FL): University of South Florida; 2005 http://ncshtc.appstate.edu/news/making-proud-choices-workshops; [accessed 06.04.16]. Louis de la Parte Florida Mental Health Institute, National Implementation Research Network. (FMHI Publication No. 231).

[5] Schalet AT, Santelli JS, Russell ST, Halpern CT, Miller SA, Pickering SS, et al. Invited commentary: broadening the evidence for adolescent sexual and reproductive health and education in the United States. J Youth Adolesc 2014;43(10):1595-610.

Corresponding author. The Department of Public Health Education, The University of North Carolina, 1408 Walker Avenue, 437 Coleman Building, Greensboro, NC 27412, USA. Tel.: +3363345532.

1. HiTOPS, Inc. works in collaboration with two other organizations to implement the Teen Prevention and Education Program (Teen PEP) in North Carolina and New Jersey. Teen PEP is a comprehensive peer-led sexual health education program geared toward increasing adolescents' knowledge, skills, attitudes and behaviors to make healthy, informed-decisions. More information can be found at http://www.teenpep.org/index.cfm.

2. Adolescent pregnancy prevention programs being implemented in $\mathrm{NC}$ included Be Proud! Be Responsible, Becoming a Responsible Teen, ¡Cuídate!, Draw the Line/Respect the Line, Making Proud Choices, Media Awareness, Reducing the Risk, Safer Choices, Smart Girls, Teen Outreach Program, Teen Prevention Education Program, Wise Guys, Adolescent Parenting Program, Be Proud! Be Responsible! Be Protective!, and Good Beginnings. 
3. The average five-year adolescent pregnancy rate was calculated using the following equation: (Number of Births + Number of Abortions + Number of Fetal Deaths)/Population. More information about calculating adolescent pregnancy rates for $\mathrm{NC}$ can be found at http://www.shiftnc.org/data/about-our-data.

4. The NC School Health Training Center (NCSHTC) recommends that counties implement a curriculum which addresses reducing risk-taking behaviors related to adolescent pregnancy, HIV and STIs. NCSHTC and PASH of NC have identified MPC as an evidence-based sexual health curriculum meeting such standards.

5. WISE and DASH are aligned with NC's HYA of 2009 by supporting counties to work with local school systems to create an environment which provides effective sexual health education. More information on WISE and DASH can be found

at http://www.cdc.gov/healthyyouth/about/index.htm. Information pertaining to NC's HYA of 2009 can be found at http://www.shiftnc.org/initiatives/working-to-institutionalize-sexeducation. 